\title{
SENTIDOS ATRIBUÍDOS POR PAIS ADOTIVOS ACERCA DA ADOÇÃO TARDIA E DA CONSTRUÇÃO DE VÍNCULOS PARENTO-FILIAIS
}

\author{
MEANINGS ATTRIBUTED BY ADOPTIVE PARENTS TO LATE ADOPTION AND \\ TO THE CONSTRUCTION OF PARENT-CHILD BONDS
}

RESUMO: Neste artigo são analisados os sentidos atribuídos por pais adotivos à construção de vínculos parento-filiais, ou seja, vinculações que pressupõem 0 sentimento de pertencimento a uma família. Apresentam-se as análises de uma pesquisa qualitativa, da qual participaram quatro pessoas (um pai e três mães) de diferentes famílias que realizaram adoção tardia e que residem na região da Grande Florianópolis (SC). Foram realizadas entrevistas semiestruturadas. As narrativas escutadas foram observadas tendo como referência teórico-metodológica a "análise de práticas discursivas e de produção de sentidos" de Spink e Medrado (2013). As análises indicaram alguns sentidos sobre a construção de vínculos parento-filiais em casos de adoção tardia, tais como: necessidade de construir uma adaptação para a criança que está sendo incluída na relação familiar; integração do passado da criança na dinâmica e na história da família atual; compreensão dos mecanismos de defesa da criança; promoção de sentimentos de pertencimento. Considera-se que a construção de vínculos parento-filiais é um indicativo do potencial sucesso da adoção; e que essa construção perpassa todo o processo, desde o período de decisão em adotar crianças até a consolidação dos vínculos parento-filiais na nova dinâmica familiar.

PALAVRAS-CHAVE: Adoção tardia; Vínculos; Parentalidade.
ABSTRACT: This paper analyses the meanings attributed by adoptive parents to the construction of parent-child bonds, that means, bonds that presuppose the feeling of belonging to a family. It presents the analysis of qualitative research, in which participated four late adopters (one father and three mothers) of different families living in the area of Greater Florianópolis (SC). Individual interviews were conducted through a semi-structured script. The narratives were analyzed according to the methodology of "discursive practices and meanings production analysis", as proposed by Spink and Medrado (2013). The analysis indicates some meanings about the construction of parent-child bonds in cases of late adoption, such as: the necessity of constructing an adaptation to the child that is being included in the new family; integration of the child's past into the dynamics and history of the current family; understanding of aversive behaviors of the child; and promoting feelings of belonging. It is considered that the construction of parent-child bonds is an indicator of potential for success of the adoption process; and that this construction runs through the whole process, since the decision-making in adopting children until the strengthening of the parent-child bonds in the new family dynamics.

KEYWORDS: Late Adoption; Bond; Parenting.
MAITÊ BROERING
FERNANDES

DANIEL KERRY DOS

SANTOS

Universidade do Sul de Santa Catarina (Unisul), Campus Grande Florianópolis/SC, Brasil

Recebido em 20/01/2019 Aprovado em 13/02/2019 


\section{INTRODUÇÃO}

Conforme Schettini, Amazonas e Dias (2006, p. 286), a adoção é considerada uma possibilidade de constituir uma família que "se não conta com os vínculos consanguíneos, está legitimamente fundamentada nos laços afetivos". Desde a promulgação do Estatuto da Criança e do Adolescente (ECA) em 1990, observam-se movimentos de criação e de fortalecimento de dispositivos e práticas que têm como prioridade atender aos direitos e ao melhor interesse das crianças e adolescentes institucionalizados e sob tutela do Estado. A adoção, em um contexto sócio-político no qual as crianças e adolescentes figuram como sujeitos de direitos, surge como uma possibilidade em recolocar esses sujeitos em um ambiente familiar no qual possam se desenvolver de forma integral. Apesar de alguns avanços, a adoção ainda é vista com preconceitos pela sociedade. Essa questão torna-se ainda mais complexa quando se trata da adoção tardia.

O interesse por esta temática surgiu quando uma das autoras deste artigo cursava uma disciplina no curso de graduação em Psicologia intitulada "Programação e Modificação de Comportamento em Contextos Diversos", na qual foi realizado um exercício prático (estágio básico) chamado "treino de pais". Nesta atividade, atendiam-se pais/mães que procuravam o Serviço de Psicologia da instituição para que pudessem ser trabalhadas demandas referentes aos seus filhos. Juntamente com colegas, a então estagiária teve contato com a temática da adoção tardia, na qual a principal queixa estava relacionada à agressividade dos/as filhos/as. Segundo o aprofundamento na atividade prática do estágio básico, percebeu-se que a demanda subjacen- te às queixas se centrava na questão da vinculação entre um dos pais e seu filho. Com isso, a primeira autora passou a desenvolver um interesse maior em estudar não apenas a adoção tardia, mas na formação dos vínculos sobretudo os vínculos parento-filiais, entre adotantes e adotados. O tema do vínculo foi ganhando cada vez mais interesse, afinal, quando a família é constituída por filhos biológicos ou bebês adotados, a vinculação é processual e ocorre com o tempo, de acordo com o crescimento da criança. Mas será que ocorre da mesma forma na adoção tardia?

Diante dessas inquietações, a autora passou por intenso processo de afetação e envolveu-se com a temática, de modo que decidiu aprofundar suas reflexões em seu Trabalho de Conclusão de Curso (TCC), o qual originou este artigo. A pesquisa desenvolvida pela primeira autora e orientada pelo segundo autor deste texto se propõe a responder a seguinte questão: quais os sentidos atribuídos por pais adotivos à construção de vínculos parento-filiais com seus filhos adotados tardiamente? A investigação teve como objetivo geral analisar os sentidos atribuídos por pais adotivos à construção de vínculos parento-filiais. Os objetivos específicos foram analisar as expectativas de pais adotivos em relação à construção de vínculos com seus filhos adotados tardiamente; compreender como os pais adotivos lidam com o processo de construção de vínculos com seus filhos adotados tardiamente; e identificar as dificuldades e facilidades na construção de vínculos entre pais adotivos e seus filhos adotados tardiamente. A finalidade da pesquisa foi propiciar um aprimoramento de conhecimentos acerca da constituição dos vínculos parento-filiais em processo de adoção tardia, pois esta 
vinculação ocorre de forma peculiar e complexa. Além disso, também procura beneficiar as comunidades acadêmicas e atuantes das áreas de Psicologia, Direito, Assistência Social, Educação e, principalmente, aqueles que trabalham com pretendentes à adoção, pais em processo de adoção e/ ou que já realizaram a adoção. Consideramos que os resultados desta pesquisa podem auxiliar na compreensão dos modos pelos quais se estabelecem vínculos parento-filiais em casos de adoção tardia, sobretudo no período de adaptação e convivência.

\section{Adoção no Brasil contemporâneo}

A adoção se constitui como um dos processos de proteção de crianças e adolescentes que se encontram em contextos de violação de direitos. Trata-se também de um dispositivo jurídico, social e cultural que busca a proteção dessas crianças e a inserção das mesmas em uma nova família. Esses processos têm como objetivo possibilitar a constituição de uma nova vinculação parento-filial, visando a garantir os direitos de desenvolvimento e potencialização do sujeito no meio familiar (Bicca \& Grzybowski, 2014; Lei n. 8.069, 1990; Pinto, 2010). Para essa finalidade, a legislação brasileira regulamentou a adoção a partir da promulgação do Estatuto da Criança e do Adolescente (ECA) - Lei no 12.010, de 2009. No Brasil, a Lei da Adoção "reflete uma mudança de concepção em relação aos direitos de crianças e adolescentes, ao voltar o foco das ações para a criança e seu bem-estar", fazendo com que esta seja uma busca de uma família para uma criança, possibilitando o fortalecimento da adoção como uma forma de melhor atender o interesse da criança (Conselho Federal de Psicologia [CFP], 2012, p. 36). Portanto, a adoção deve possibilitar o exercício da paternidade e da maternidade aos/ às pretendentes à adoção e, principalmente, permitir que a criança seja inserida em uma nova família que assegure os seus direitos e garanta sua proteção biopsicossocial (Schettini et al., 2006). Vale destacar que, em 2017, o Governo Federal aprovou a Lei 13.509/2017, que também dispõe sobre a adoção e altera o ECA. Essa nova lei objetiva acelerar o processo de adoção, ao buscar assegurar a prioridade e celeridade nos processos de adoção de grupos de irmãos, crianças e/ou adolescentes, pessoas com doenças crônicas, e/ou com necessidades específicas de saúde. Observa-se, portanto, que a criação de dispositivos jurídicos que garantam que crianças institucionalizadas fiquem menos tempo à espera da adoção é uma problemática em contínua construção e uma preocupação ainda recente no Brasil.

Outro documento importante que diz respeito às políticas de adoção no Brasil é o "Plano Nacional de Promoção, Proteção e Defesa do Direito de Crianças e Adolescentes à Convivência Familiar e Comunitária" (Ministério do Desenvolvimento Social e Combate à Fome [MDS], 2006, p. 47). Tal documento estabelece as seguintes diretrizes para os casos de adoção: (a) que a adoção deve ser aplicada apenas quando não há possibilidade de manter a criança ou adolescente na família de origem; (b) que, nestes casos, a adoção deve ser tratada como prioridade "em relação a outras alternativas de longo prazo, uma vez que possibilita a integração, como filho, a uma família definitiva, garantindo plenamente a convivência familiar e comunitária"; (c) que a adoção deve 
unir as prioridades e vontades dos adotantes e adotados; d) que as crianças e adolescentes fiquem sob tutela do Estado somente até a integração a uma família permanente, onde os adotados possam encontrar um ambiente que permita a continuidade do seu desenvolvimento.

Denomina-se adoção tardia quando nos referimos à adoção de crianças e adolescentes com idade superior a dois anos. Costa e Rossetti-Ferreira (2007) e Machado, Ferreira e Serón (2015) questionam a utilização deste termo e sugerem a categoria "adoção de crianças maiores" para se referirem a essa modalidade de adoção. Tal crítica assinala a intenção de certificar de que não há tempo exato para a adoção, já que a palavra "tardia" pode levar ao entendimento de que o tempo apropriado para a adoção já se passou. Bicca e Grzybowski (2014) também fazem tal discussão, mas optam pelo termo "adoção tardia" por este ser amplamente utilizado na literatura e em documentos oficiais. Com base nestas discussões, optou-se, neste artigo, por fazer uso do termo mais recorrente, tanto na literatura como nos documentos oficiais. Apesar das contradições dos termos, não podemos desconsiderar que à medida que aumenta o tempo de institucionalização das crianças, menores serão as chances de serem adotadas.

No Brasil, muitas pessoas procuram a adoção como meio de tornar real o desejo da parentalidade. Segundo dados da pesquisa realizada pelo Conselho Nacional de Justiça (2013), existem 28.151 pessoas cadastradas, sendo que $92,7 \%$ têm preferência por crianças entre zero e cinco anos de idade. Por outro lado, em situação de acolhimento em instituições, existem 40.340 crianças, sendo que apenas 5.281 estão aptas para adoção. Destas,
91,2\% são crianças e adolescentes a partir dos seis anos de idade. Percebe-se, portanto, uma divergência entre a realidade das crianças disponíveis para adoção e a preferência de adotantes (Bicca \& Grzybowski, 2014, p. 156). Diante desse quadro, Cananéa (2016) ressalta o impacto da cultura atual na adoção tardia, pois tais mitos facilitam situações de abandono contínuo e histórias e vivências difíceis, além de serem estigmatizadas socialmente como "crianças- problema".

Objetivando a transformação de uma cultura que dificulta a adoção tardia, observa-se a atuação de vários grupos de apoio e de estudos, como se pode constatar, por exemplo, no site da Associação Nacional de Grupos de Apoio à Adoção (ANGAAD $)^{1}$. Além desses grupos, também temos observado campanhas e programas que visam à promoção dessa modalidade de adoção. Tais movimentos tentam conscientizar a sociedade e os futuros pretendentes à adoção sobre a situação destas "crianças mais velhas" e os benefícios que estas podem usufruir ao serem adotadas. Segundo Bicca e Grzybowski (2014), a existência destes grupos favorece pretendentes à adoção, adotantes e principalmente crianças e adolescentes que se encontram em instituições de acolhimento.

Autoras como Sampaio, Magalhães e Féres-Carneiro (2018) e Schettini et al. (2006) relatam que os pretendentes resistem à adoção tardia por conta de medos relacionados à dificuldade em educar uma criança mais velha e à adaptação com crianças que já possuem vivências anteriores. Estas características costumam aparecer durante o período de adaptação da criança no novo núcleo familiar e ao longo do trabalhoso processo de construção de vínculos. conferir 0 site: http://www. angaad.org.br. 
Adoção tardia e a construção dos vínculos parento-filiais

Segundo Cananéa (2016), uma vez que a adoção se configura como uma medida de proteção, ela assegura o direito da criança e do adolescente de se desenvolverem em um núcleo familiar, mas não garante a existência, a construção e a manutenção de vínculos afetivos. Conforme destacam Bicca e Grzybowski (2014, p. 156), o processo de adoção se instaura "no ponto de partida para uma nova fase na vida do adotando, a partir da vinculação com a família adotiva”. Assim, a construção de vínculos parento-filiais é um dos grandes indicativos do potencial sucesso da adoção. $\mathrm{Na}$ adoção tardia, por já haver uso de linguagem e vivências passadas, é necessário que haja outros modos de vinculação afetiva, o que a diferencia de uma adoção convencional de bebês (Sampaio et al., 2018). Segundo Costa e Rossetti-Ferreira (2007, p. 431), "na adoção tardia, as crianças negociam também a afetividade e a construção de seu amor filial". Com isso, a vinculação deve ser construída envolvendo este/a novo/a filho/a, fazendo com que este/a se implique de forma ativa nas novas relações familiares.

Para Schettini et al. (2006, p. 289), "na adoção... a constituição da identidade parental demanda ...um processo de identificação com os novos atributos através de uma gestação psicológica". Conforme apontam Pinto (2010) e Schettini et al. (2006), alguns autores postulam que na adoção ocorreria a chamada "gestação psíquica", processo psicológico através do qual os/as adotantes passam a construir sentidos a respeito da criança ou adolescente a ser adotado. Para Bicca e Grzybowski (2014), esse processo seria essencial para a formação dos vínculos parento-filiais.

A construção dos vínculos parento-filiais é diferente para cada família e para cada um dos sujeitos nela envolvidos. As vivências pregressas dos pais e dos filhos atravessam tal construção vincular, exigindo um processo de implicação nesta relação (Sampaio et al., 2018). Bicca e Grzybowski (2014) e Costa e Rossetti-Ferreira (2007) apontam que se observa a possibilidade de haver dificuldades que permeiam todas as famílias adotantes, bem como seu entorno, que muitas vezes é marcado por diversos preconceitos e despreparos, dificultando o reconhecimento da nova configuração familiar. De acordo com Levinzon (2004, p. 132 como citado em Pinto, 2010, p. 47), "o grande desafio da família adotiva encontra-se na aquisição e fortalecimento do sentimento de filiação". Ou seja, nos processos de adoção não basta somente criar vínculos, mas propiciar também um sentimento de pertencimento em todos os envolvidos no núcleo familiar. Pinto afirma que é possível estabelecer apenas vínculos afetivos, sem que haja vínculos de filiação; nestes casos, a autora relata que a criança ainda se encontra abandonada, pois subjetivamente não houve a adoção da criança na dinâmica familiar. A autora ainda aponta que:

Uma criança adotada pode adaptar-se facilmente ao contexto familiar, aos costumes e hábitos da família constituída, mas isso não implica que tenha se estabelecido o 'sentimento de familiaridade’ ... Do mesmo modo, manter uma relação afetivamente positiva com os pais 
adotivos também não consiste na garantia por si só do estabelecimento de um vínculo de filiação entre eles. (Pinto, 2010, p. 58)

Um dos maiores receios apontados por pretendentes à adoção tardia é a existência de sofrimentos advindos da convivência com a família de origem ou até mesmo da instituição de acolhimento (Bicca \& Grzybowski, 2014; Schettini et al., 2006). A existência de sofrimentos vivenciados $a$ priori pode acarretar eventuais dificuldades na construção dos vínculos e das relações com a nova família. $\mathrm{Na}$ pesquisa desenvolvida por Sampaio et al. (2018), ao entrevistar pais que realizaram adoção tardia, observou-se uma apreensão frente aos costumes e aprendizados adquiridos pela criança anteriormente à adoção. Tais dimensões foram consideradas um dos principais obstáculos iniciais na construção do vínculo parento-filial. As autoras relatam que as vivências passadas das crianças podem ter deixado marcas e emoções desagradáveis que potencialmente terão efeitos nas futuras vinculações, por conta do rompimento precoce de vínculos familiares, do abandono e da negligência sofridos na família biológica e nas instituições de acolhimento.

De acordo com Sampaio et al. (2018), as crianças adotadas já passaram por vivências de rupturas. Tais rupturas acontecem tanto em relação às famílias de origem como em relação às mudanças de ambientes - quando as crianças são levadas a trocar da instituição de acolhimento com a qual possuem vinculações para um novo ambiente desconhecido, no qual irão habitar com a família adotiva. Silva et al. (2014 como citado em Sampaio et al., 2018) consideram que estas rupturas impactam diretamente na construção de novos vínculos pela criança adotada, pois demandam dela um grande esforço psíquico para permitir se posicionar novamente em uma família.

Sampaio et al. (2018) afirmam que, devido à existência de vivências anteriores à adoção, a construção de vínculos com os pais adotivos pode se iniciar fragilizada, já que tanto os pais quanto as crianças devem se adaptar aos modos de viver de cada um. Conforme apontam as autoras:

pode-se dizer que a construção do vínculo parento-filial será permeada pelas vivências anteriores, tanto dos pais quanto das crianças, num processo que demanda construção de ambas as partes, considerando que a criança, muitas vezes, já é capaz de discernir o que deseja e compreender a adoção. (Sampaio et al., 2018, p. 313)

Um dos momentos importantes para a construção dos vínculos parento-filiais é o período de adaptação - ou estágio de convivência, que, segundo Bicca e Grzybowski (2014), é o período entre a assunção da guarda do adotando e a homologação da sentença de adoção. As autoras destacam que é nesta etapa que os pais poderão conviver com seus filhos, podendo ser auxiliados por técnicos como assistentes sociais e psicólogos. Costa e Rossetti-Ferreira (2007) definem este período como frágil, uma vez que se trata do momento no qual os vínculos parento-filiais estão sendo negociados e construídos.

Paiva (2004 como citado em Alvarenga \& Bittencourt, 2013) ressalta a importância dos períodos de adaptação, pois é neste momento que os pais adotivos poderão elabo- 
rar uma condição de parentalidade, além de se adaptarem às mudanças resultantes da chegada de uma criança, principalmente quando se trata de adoção tardia. Assim, conforme salientam Alvarenga e Bittencourt (2013), a existência de um estágio de convivência legalmente deferido - que ocorre previamente à adoção - deve ser valorizado, pois essas interações permitem que dificuldades e dúvidas presentes possam ser solucionadas.

Schettini et al. (2006, citado em Bicca \& Grzybowski, 2014) salientam que a vinculação afetiva no período de convivência é um processo que exige tempo e trabalho para fazer com que a criança crie seguranças e que os pais passem a aceitar, perceber e sentir a criança como seu filho. Apesar de haver a idealização do filho, os pais devem compreender que esta criança já pode ser capaz de discernir o que deseja e de lidar com sofrimentos resultantes da vivência em instituições de acolhimento ou na própria família de origem (Sampaio et al., 2018; Schettini et al., 2006). Assim, Bicca e Grzybowski (2014), Sampaio et al. (2018) e Schettini et al. (2006) apontam para a necessidade de também integrar estas vivências anteriores à sua história de vida, já que estas fazem parte de sua identidade e, por isso, não se deve negar seu passado.

Ao abordar a questão da adoção tardia, é indispensável que haja uma reflexão do histórico e das vivências prévias à adoção para que seja possível apreender a construção de um novo vínculo parento-filial (Sampaio et al., 2018). As autoras mencionam diversas pesquisas que indicam a importância de reconhecer e validar o passado da criança, "dando espaço para que o histórico possa ser recontado e não ocupe o espaço de fantasma na relação familiar". Assim, Levinzon (2004 como citado em Schettini et al., 2006) relata que, se os pais tiverem consciência de seu poder de fazer diferença e de exercer um papel ativo na construção de uma nova vivência para a criança, mais preparados estarão para conviver com ela de forma a reestruturar seu modo de viver e interagir.

\section{METODOLOGIA}

\section{Delineamento da pesquisa e participantes}

A pesquisa que deu origem a este artigo caracterizou-se como qualitativa, de corte transversal, exploratória e de estudo de campo. Participaram pais que realizaram o processo de adoção tardia e que frequentam grupos de estudos e apoio à adoção na Grande Florianópolis. $\mathrm{O}$ critério de inclusão foi selecionar os primeiros pais contatados que realizaram a adoção tardia há no mínimo um ano e no máximo dez anos. Estabelecemos esse tempo mínimo por considerarmos que nesse espaço temporal os/as adotantes já poderiam expressar sentidos atribuídos à experiência da adoção tardia. $\mathrm{O}$ tempo máximo foi estabelecido tendo em vista da não utilização de um recorte temporal não muito longo, o que provavelmente acarretaria diferenças culturais e históricas na produção dos sentidos dos/das interlocutores/ as. Inicialmente, foi proposta a realização de seis entrevistas, podendo ser individuais ou com o casal, se fosse o caso. Porém, devido aos obstáculos referentes aos critérios de inclusão e à disponibilidade de horários dos participantes, foram realizadas quatro entrevistas, sendo todas individuais. 
Para obter o contato com os participantes, foi realizada a aproximação com os responsáveis por um grupo de estudos e apoio à adoção da região da Grande Florianópolis, para os quais foi apresentada a proposta da pesquisa. Posteriormente, foi solicitada uma mediação entre a pesquisadora principal e os possíveis participantes para a pesquisa. Além disso, a pesquisadora participou de encontros de discussão do grupo, que eram compostos por membros da instituição, famílias que já haviam realizado a adoção, famílias pretendentes a adotar crianças e demais pessoas interessadas no tema. Após o aval dos responsáveis pelo grupo, os mesmos adicionaram a pesquisadora a um grupo de um aplicativo de mensagens instantâneas, por meio do qual se pôde explicar sobre a pesquisa. A partir desse grupo, os/as interessados/as em participar se manifestaram e, foi possível, por fim, agendar as entrevistas, explicar os procedimentos de pesquisa e as questões éticas subjacentes à investigação.

\section{Procedimentos e instrumento}

Por se tratar de uma pesquisa com seres humanos, foi prevista a possibilidade de haver riscos. Assim, no momento anterior à realização das entrevistas, foi apresentado aos entrevistados o Termo de Consentimento Livre e Esclarecido (TCLE), objetivando esclarecer os objetivos, riscos e benefícios da pesquisa. Todos/as os/as participantes leram, concordaram e assinaram esse termo. A pesquisa foi aprovada pelo Comitê de Ética de Pesquisa da Universidade do Sul de Santa Catarina (Unisul), Unidade Grande Florianópolis.
Os dados foram obtidos por meio de entrevistas semiestruturadas, realizadas a partir de um roteiro previamente elaborado, construído segundo os objetivos da pesquisa. O roteiro de entrevista possuía 15 questões com as seguintes temáticas: a) motivação e decisão pela adoção tardia; b) primeiro contato; c) expectativas; d) período de adaptação; e) construção de vínculos; f) sentir-se e ser considerado pai/mãe; g) relação atual. As entrevistas tiveram duração de 30 a 60 minutos, foram áudio gravadas, transcritas e analisadas e ocorreram em locais definidos previamente pelos participantes, dando prioridade a lugares acessíveis e que garantissem o sigilo, o anonimato e a privacidade durante a condução questões.

A análise das respostas foi realizada em diálogo com a literatura estudada e tendo como referência teórico-metodológica a metodologia de análise de práticas discursivas e de produção de sentidos. De acordo com Spink e Medrado:

O conceito de práticas discursivas remete ... aos momentos de ressignificações, de rupturas, de produção de sentido, ou seja, corresponde aos momentos ativos do uso da linguagem, nos quais convivem tanto a ordem como a diversidade. (Spink \& Medrado, 2013, p. 27)

De acordo com a perspectiva teórico-metodológica proposta pelos autores supracitados, é por meio das práticas discursivas que se torna possível se posicionar nas relações cotidianas e produzir sentidos. Portanto, para analisarmos as práticas discursivas, é necessário compreender também a produção de sentidos que se agenciam em contextos situ- 
ados. Os sentidos, segundo Spink e Medrado (2013), são construções sociais a partir das quais as pessoas interpretam, significam e organizam as situações e os fenômenos de suas vidas. Spink e Medrado (2013, p. 23) apontam que a produção de sentidos não é uma "simples reprodução de modelos predeterminados" e não representa uma dimensão intrapsíquica de indivíduos isolados das suas relações sociais. Nessa perspectiva teórico-metodológica, apontamos a fundamental importância de considerarmos as negociações de sentidos - compreendidos como fenômenos sociolinguísticos, que são operadas desde uma contingência histórica, política, econômica, cultural e social. Desse modo, a produção de sentidos precisa ser analisada em suas situacionalidades, polissemias, ambiguidades, contradições e condições dialéticas e históricas de existência.

A perspectiva da "análise de práticas discursivas e de produção de sentidos" se localiza no campo epistemológico do construcionismo social, que, de acordo com Spink e Medrado (2013, p. 40), busca "identificar os processos pelos quais as pessoas descrevem, explicam e/ou compreendem o mundo em que vivem, incluindo elas próprias”. Distancia-se, assim, de certas tradições hegemônicas no campo da psicologia, que historicamente investiram em perspectivas epistemológicas alicerçadas em concepções essencialistas e a-históricas que visam à descrição de supostas interioridades dos sujeitos e que reproduzem dicotomias estanques como interno/externo, público/privado, sujeito/objeto, etc.

Diante desse marco teórico-metodológico, em nossa pesquisa busca- mos analisar os sentidos atribuídos por pais adotivos à construção de vínculos parento-filiais com seus filhos adotados tardiamente. Em relação à temporalidade expressa na interanimação dialógica construída por meio das entrevistas, focamos fundamentalmente em duas dimensões das experiências dos interlocutores: o tempo vivido e o tempo cur$t^{2}$. De acordo com Spink e Medrado (2013, p. 33), o tempo vivido "corresponde às experiências da pessoa no curso da sua história pessoal" e representa "o tempo da memória traduzida em afetos ... nosso ponto de referência afetivo, no qual enraizamos nossas narrativas pessoais e identitárias". Já o tempo curto corresponde à dialogia propriamente dita, ou seja, é aquela temporalidade que nos possibilita entender as produções de sentidos comunicadas face a face, sempre polissêmicas e inscritas em múltiplos repertórios.

Considerando tais marcos temporais nas construções de sentidos, o conteúdo das entrevistas foi organizado a partir de categorias de análise divididas em "dois momentos": (a) momento pré-adoção, no qual foram analisados os sentidos atribuídos às situações prévias à chegada da criança na família; e (b) momentos pós-adoção, no qual foram analisados os sentidos atribuídos à construção de vínculos no período de adaptação, bem como os sentidos atribuídos aos atuais vínculos parento-filiais. No item a seguir, apresentamos nossas análises desenvolvidas a partir do material dialógico compartilhado no processo da pesquisa.
${ }^{2}$ Spink e Medrado (2013), em suas pesquisas no campo da Psicologia Social, apontam a necessidade de se analisar as práticas discursivas e as produções de sentidos na interface de três tempos históricos: 0 tempo longo, o tempo vivido e o tempo curto. Por uma questão de recorte metodológico, focamos nas temporalidades relativas aos tempos curto e vivido. Não desconsideramos, com isso, a importância de um aprofundamento das questões aqui levantadas a partir de um enfoque no tempo longo. 


\begin{tabular}{|c|c|c|c|c|c|}
\hline Nome & Idade & $\begin{array}{l}\text { Configuração } \\
\text { familiar }\end{array}$ & $\begin{array}{c}\text { Crianças adotadas } \\
\text { e idade atual }\end{array}$ & $\begin{array}{l}\text { Idade das } \\
\text { crianças no } \\
\text { momento da } \\
\text { adoção }\end{array}$ & $\begin{array}{l}\text { Ano em } \\
\text { que a } \\
\text { adoção foi } \\
\text { realizada }\end{array}$ \\
\hline Matheus & 41 anos & Monoparental & $\begin{array}{c}\text { Eduardo, 21; Carolina, } 15 \\
\text { (parte de grupo de irmãos } \\
\text { biológicos) }\end{array}$ & $\begin{array}{l}15 \text { anos; } \\
9 \text { anos }\end{array}$ & 2012 \\
\hline Andreia & 43 anos & Heteroparental & $\begin{array}{l}\text { Sofia, 11; Amanda, } 6 \\
\text { (irmãs biológicas) }\end{array}$ & $\begin{array}{l}6 \text { anos; } \\
\text { meses }\end{array}$ & 2013 \\
\hline Luciana & 47 anos & Heteroparental & $\begin{array}{c}\text { Mariana, } 12 \\
\text { Beatriz, 12; Letícia, 9; } \\
\text { Giovana, } 7 \\
\text { (irmãs biológicas) }\end{array}$ & $\begin{array}{l}\text { meses } \\
5 \text { anos; } \\
3 \text { anos; } \\
3 \text { meses }\end{array}$ & 2006 \\
\hline $\begin{array}{c}\text { Maria } \\
\text { Aparecida }\end{array}$ & 60 anos & Monoparental & $\begin{array}{c}\text { André, 17; Raquel, } 16 \\
\text { (parte de grupo de irmãos } \\
\text { biológicos) }\end{array}$ & $\begin{array}{l}9 \text { anos; } \\
8 \text { anos }\end{array}$ & 2010 \\
\hline
\end{tabular}

\section{RESULTADOS E DISCUSSÃO}

Para uma melhor compreensão do contexto do/das entrevistado/as, a tabela a seguir apresenta as seguintes informações: nome, idade, configuração familiar, nome das crianças adotadas e idades atuais, idades das crianças no momento da adoção, e ano em que a adoção foi realizada. Os nomes do/das entrevistado/as e de seus/suas filhos/as foram substituídos por nomes fictícios, com a finalidade de garantir sigilo.

\section{Momento pré-adoção: motivações e expectativas}

Ao analisar os sentidos atribuídos à construção de vínculos na adoção, percebeu-se, por meio das entrevistas, que tal construção é um processo que surge antes da adoção, quando os então pretendentes estão motivados a adotar. Ou seja, neste momento, os pretendentes já estão abertos a receberem uma família, pois já passaram por cursos de preparação para adoção e por um tempo de espera. Assim, con- forme apontado no estudo feito por Bicca e Grzybowski (2014), é importante que os/as pretendentes se permitam acolher as crianças, considerando que as mesmas já possuem vivências afetivas, emocionais e subjetivas, pois isso contribuirá para a abertura de uma construção de vínculos. Além disso, a disposição e o desejo dos pretendentes em serem pais também viabilizam a formação dos vínculos.

Observou-se, entre os entrevistados, que o discurso em comum apresentado é sobre o desejo em ser pai e/ ou mãe e possuir uma família. Porém, cada sujeito tem sua história de vida singular que o levou a esta decisão, como esterilidade, no caso de Luciana; desejo de não ter filhos biológicos, no caso de Andreia; e construir uma família monoparental, nos casos de Matheus e Maria Aparecida. De acordo com Bicca e Grzybowski (2014), "o desejo de exercer a parentalidade parece se sobrepujar a características específicas das crianças, ou seja, os casais querem vivenciar a maternidade e a paternidade acima de tudo". Conforme Schettini et al. (2006), o principal fator para tal desejo está associado às mu- 
danças nas configurações familiares, $o$ que proporciona que a adoção ocorra das mais diversas maneiras e em variados contextos. Ou seja, o desejo pela adoção possibilita que os pretendentes escolham adotar não apenas por condições biológicas, como a infertilidade, mas também por almejarem construir ou ampliar suas famílias, independente da configuração familiar (Schettini et al., 2006, p. 286). Assim, o processo de adotar tem a função de realizar o desejo de se tornarem pais.

O desejo de se sentirem e de se tornarem pais contribui para que a adoção seja um dispositivo capaz para auxiliar as crianças institucionalizadas a encontrarem uma família. A adoção, porém, não deve ser realizada como caridade, já que se trata de um processo no qual as crianças devem ser integradas à família como sujeitos que pertencem efetivamente a esse novo território familiar. Conforme aponta Luciana: "Eu acho que se você quer ajudar, não adote, ajude de outra forma, né?".

Para Schettini et al. (2006, p. 286), "a prática da adoção de crianças não pode estar associada a um caráter assistencial ou filantrópico, tampouco servir a fins egoístas para suprir faltas subjetivas dos adotantes". Deve-se, ademais, considerar sempre o lugar da criança na relação familiar e as funções que cada um deverá exercer. Luciana complementa sua fala: "eu acho que quem tá adotando tem que ter isso em mente ... que você vai construir uma família com essa criança que tá entrando no teu lar".

Além da escolha pela adoção, há também a decisão pela adoção tardia. Observou-se que a decisão por essa modalidade de adoção é influenciada, nesses casos, principalmente pelo fato de não haver a necessidade de cuidados com bebês.
Na adoção tardia você não passa por aqueles percalços de um bebê, ... eles já vêm maiores, é muito mais tranquilo, assim, de diálogo ... eles entendem as coisas com mais facilidades. (SIC Maria Aparecida)

Este sentido também aparece nos casos de Andreia e Luciana, que também realizaram "adoção convencional", ou seja, de bebês. Luciana relata: "quando eu decidi ter mais filhos, eu decidi que eu não queria passar por aquilo de novo". Compreendemos que, socialmente, é comum o compartilhamento do sentido de que cuidar de um bebê exige maior dedicação e tempo do que os cuidados dispensados a uma criança que já tem maior compreensão de mundo e que sabe expressar suas vontades. Essa concepção, reproduzida pelos interlocutores, foi acionada como justificativa para escolha pela adoção tardia. De modo semelhante ao que foi apontado no estudo feito por Bicca e Grzybowski (2014), os entrevistados percebem que a adoção tardia é mais "tranquila" e "vantajosa" do que a adoção convencional, pois, com mais idade, a criança já possui certa independência e já tem a capacidade de interagir de maneira mais ativa.

Durante o tempo de espera pela adoção, é comum que os/as pretendentes tenham expectativas sobre a adoção e sobre os/as futuros/as filhos/as. Porém, ao serem questionados sobre este tema, os entrevistados demonstraram não possuírem muitas expectativas em relação à criança, de modo que estavam mais focados em realizar seus desejos de serem mãe/ pai. De acordo com Vargas (1998, p. 40), quando os pais projetam suas expectativas (e do restante da família) na criança a ser adotada, já se estabelecem alguns percursos que fazem parte do processo de adoção tardia. Consi- 
deramos que, ao se disponibilizarem e se manterem abertos à chegada dos filhos, preocupando-se apenas em atender às necessidades de ambas as partes, os participantes possibilitam a construção de caminhos para uma vinculação menos marcada (porém, evidentemente, não totalmente livre) por projeções e idealizações. De acordo com as narrativas, essa postura facilitaria a adaptação da criança no novo ambiente familiar.

$\mathrm{O}$ primeiro contato entre os entrevistados e seus (futuros) filhos ocorreu já após a habilitação para adoção. Esse processo foi mediado pelo judiciário, como nos casos de Matheus e Luciana; e pelo trabalho voluntário, como nos casos de Andreia e Maria Aparecida. Este é mais um passo para a construção de vínculos entre pais e filhos, pois, neste momento, os pretendentes já visualizam, de forma mais concreta, a possibilidade de terem filhos. No que se refere ao primeiro contato, há também uma importante questão: o fato de haver ou não um suposto "amor à primeira vista". Para Andreia, Luciana e Matheus, este amor à primeira vista é uma "fantasia". Matheus menciona: "O amor, ele não acontece de forma mágica nem espontânea. Não existe amor à primeira vista, então ele vai ser construído". Ou seja, podemos perceber o sentido de que o amor existirá, porém será construído na convivência e em conjunto com o filho adotado. Maria Aparecida, por sua vez, apesar de concordar que é uma "construção coletiva", traz uma reflexão de que haveria um "amor à primeira vista", referindo-se à adoção como sendo uma "escolha do coração”. Compreende-se, portanto, que a questão da construção do amor é subjetiva, situacional e singular. Todos os participantes, no entanto, parecem concordar que nesse quesito não haveria "certo ou errado", e que se trata de uma construção e de adaptações entre os membros que constituem a família.

O que se observa, por conseguinte, é que os momentos que antecedem a ida do adotado à residência da família adotiva são repletos de conquistas para os adotantes: a escolha pela adoção, a efetivação do Cadastro Nacional de Adoção e o estabelecimento do perfil do adotado, as entrevistas com os profissionais do fórum, o primeiro contato com as crianças, o período de convivência e a obtenção da guarda. Assim, após estes momentos, os adotantes e adotados se encaminham para um novo momento, no qual é demarcada uma nova temporalidade na experiência da adoção: o período de adaptação e da construção dos vínculos parento-filiais. A seguir, analisamos alguns dos sentidos que se produzem nesse marco temporal.

\section{Momentos pós-adoção: adaptação e vínculos}

O período de adaptação tem seu início quando a criança passa a morar com a família adotiva. Para os participantes, este período é correspondente ao primeiro e segundo ano do convívio diário com família. Como falado anteriormente, há, durante o estágio de convivência, a possibilidade de ter acompanhamento de técnicos do fórum. Contudo, nenhum dos entrevistados recebeu esses acompanhamentos durante ou após este período. Além disso, Maria Aparecida comenta sobre a morosidade do judiciário e o "abandono" após a adoção, isto é, profissionais do fórum e do judiciário não contatam mais os pais ou as crianças depois que é dada a guarda, de modo que não houve um 
acompanhamento ou segurança para a família. O relato de Maria Aparecida coaduna com as reflexões de Machado et al. (2015, p. 78), que afirmam que, para haver a habilitação para adoção no Brasil, deve haver também um "trabalho específico com os postulantes a adotantes, mas na maioria das vezes o judiciário não consegue acompanhar todos os processos".

Para Bicca e Grzybowski (2014, p. 157), o período de convivência na adoção tardia traz algumas particularidades, pois a criança adotada já apresenta postura ativa, envolvendo-se na dinâmica familiar e apresentando vivências anteriores que refletem "no seu estilo de viver, aprender, sentir e pensar". Os participantes relataram algumas dificuldades enfrentadas durante este período de convivência, tais como os efeitos dos cuidados que as crianças receberam na instituição, adaptação da família, falta de apoio, rejeição da maternidade/paternidade e a história prévia da criança. Frente a essas questões, o entrevistado Matheus cita que deve haver "mais paciência do que amor".

Quando a criança fica institucionalizada por um longo período, ela se acostuma com o ambiente, com a rotina e com outras crianças com quem convive. Matheus e Maria Aparecida denominam essas crianças de "falsos mimados". De acordo com o/a entrevistado/a, apesar de a instituição estar abrigando e fazendo seus deveres, não há, nestes casos, uma condição de limite ou cuidado das situações da rotina da criança. Essas percepções de Matheus e Maria Aparecida corroboram as reflexões de Sampaio et al. (2018), que afirmam que é comum que em instituições de acolhimento a rotina não favoreça o aprendizado de cuidados essenciais. Segundo as autoras, "a predominância da função assis- tencialista, somada à falta de estrutura dessas instituições, fragiliza o compromisso voltado ao desenvolvimento da infância e da adolescência" (Sampaio et al., 2018, p. 316).

Dessa forma, quando as crianças são adotadas e passam a residir com a família adotiva, elas podem não conhecer alguns limites e situações que ocorrem em residências familiares. Matheus e Maria Aparecida relataram ter vivenciado tais dificuldades, nas quais os filhos não tinham noção de uso de roupas ou da reposição de alguns objetos e materiais. Assim, os pais adotivos devem assegurar à criança que compreenda o novo ambiente e os limites, regras e a organização, mas também devem compreender e procurar adaptar estas questões com seus filhos, para que entendam os pontos de vista e que haja um consenso entre as partes.

Outra questão difícil encontrada é relacionada à adaptação da família ou casal para as crianças que estão chegando. Luciana aborda essa questão:

Eu pensei que eu teria que adaptar três filhas à minha família e foi $o$ contrário. Eu tive que adaptar a minha família com filha única a uma nova família que tava chegando, porque elas eram uma família. (SIC Luciana)

Bicca e Grzybowski (2014) descrevem os comportamentos de acolhimento e disponibilidade para a construção do vínculo, na qual compreendem que é necessário que haja uma adaptação de todos os membros e não apenas da criança. Ou seja, deve-se entender as dificuldades de ambas as partes que estão envolvidas, procurando não perceber este momento de forma negativa, mas de forma compreensiva. 
Uma dificuldade relatada pelos entrevistados é a falta de uma rede apoio. Compreende-se que "ter apoio" pode facilitar a situação de adaptação. Essas redes de apoio podem se constituir por amigos, parentes ou grupos de apoio, servindo não só para auxiliar na prática e nos cuidados, mas também para acolher ou compreender esta nova vivência. Schettini et al. (2006) pontuam que participar de grupos de apoio à adoção possibilita aos pretendentes trocar experiências e favorece a preparação dos mesmos para lidarem com dificuldades e ansiedades que são frequentes no processo de adoção.

Nos casos de adoção tardia, é comum que as crianças tenham conhecimento e lembranças sobre os pais biológicos e sobre o tempo em que passaram na instituição de acolhimento. Os entrevistados relataram que, devido a essa consciência, é frequente o aparecimento de problemas que levam as crianças a rejeitarem a nova figura paterna/materna. Possivelmente, tais rejeições e/ou problemas de relacionamento durante o processo de vinculação estejam relacionados a mecanismos de defesa da criança que podem ser acionados como forma de responder a angústias por conta de fantasias de abandono, já vivenciadas na família de origem ou até de outras famílias adotivas. Nesses casos, a criança se esforça para não se apegar, com medo de ser novamente rejeitada. Apesar de perceberem essa dinâmica em suas experiências, os pais entrevistados mostraram-se compreensivos, procurando sempre reafirmar a paternidade/maternidade e o desejo de que as crianças permanecessem na família e no lar.

Bicca e Grzybowski (2014), Costa e Rossetti-Ferreira (2007), Sampaio et al. (2018) e Schettini et al. (2006) assinalam as dificuldades encontradas na adoção tardia, sobretudo relacionadas com as vivências pregressas da criança. $\mathrm{Na}$ adoção tardia, a criança possui lembranças de situações passadas, vivenciadas com a família de origem e no abrigo, que geralmente se distinguem do que viverão após serem adotadas. Além disso, há uma grande chance de que essas vivências tenham sido experienciadas de forma sofrida, porém este repertório afetivo é desconhecido e de difícil acesso por parte dos pais adotivos, conforme sinaliza Luciana:

Foi difícil presenciar certas realidades que ela viveu que eu não esperava, eu não esperava que isso fosse se manifestar ... Então são coisas assim da realidade dela que chocou muito, né, porque eu não imaginava que isso iria acontecer. Eu achei que ela ia vim e que ela ia conhecer a nossa realidade e ela ia funcionar conforme a nossa realidade. (SIC Luciana)

De acordo com Schettini et al. (2006, p. 291), as vivências anteriores da criança representam uma parte peculiar de sua identidade que não pode ser negada ou anulada, "mas que o filho adotado necessita que seja aceita e integrada à sua nova ligação afetiva”. Desta forma, segundo Sampaio et al. (2018), quando a criança é inserida em um novo contexto familiar por meio da adoção, ocorre um momento de ressignificação destas experiências pregressas, que compõe parte do processo de construção da identidade da criança. Por isso, faz-se necessário discutir sobre estas vivências e integrá-las à vida da criança. Luciana relata sua experiência em relação a esse processo:

Não quero apagar o que ela viveu, eu quero tentar realmente deixar muito no subconsciente as coisas ruins que 
ela viveu, mas que ela teve uma mãe, uma outra mãe, um outro pai e isso eu acho que ela não pode esquecer nunca, né, porque isso faz parte da vida dela, da história dela e da formação dela. (SIC Luciana)

Os pais também precisam saber conviver com essa situação, já que não podem excluir da vida da criança suas experiências pregressas ou esperar que isso seja omitido. Para que isso ocorra, Costa e Rossetti-Ferreira (2007, p. 433) salientam que "os pais devem favorecer oportunidades de conversa com a criança sobre seu passado, de modo aberto e não defensivo". De acordo com as autoras, esses espaços de conversa teriam por finalidade propiciar a formação de narrativas sobre o passado, sem que a criança se sinta na obrigação de escolher um dos lados pais biológicos ou pais adotivos.

Em geral, nos casos de adoção tardia as crianças estão cientes de que estão sendo adotadas. Apesar desta ciência, é possível que a criança tenha incertezas sobre alguns fatos relacionados à adoção (Costa \& Rossetti-Ferreira, 2007). Dessa forma, apesar de a adoção possibilitar uma nova realidade para a criança adotada, não podemos negar suas vivências prévias, pois nelas o sujeito em questão obteve aprendizados, erros, conquistas, construiu parte de sua identidade e subjetividade, além de ter estabelecido vínculos que provavelmente serão importantes para a sua vida.

Para além das dificuldades que ocorrem no período de convivência, os entrevistados apresentam facilidades identificadas neste período, tais como a capacidade de compreensão das crianças maiores; a participação em grupos de apoio à adoção; e a necessidade de troca de carinho e cuidado entre as partes. Diferentemente de um bebê, quando a criança é adotada tardiamente, a mesma já consegue ter certo grau de entendimento acerca das próprias vivências, do acolhimento e do processo de adoção. Todas essas características percebidas nas crianças foram consideradas como uma facilidade para os entrevistados. Esta questão é fundamental na escolha pela adoção tardia, pois os pais têm a possibilidade de desenvolver, em parceria com a criança, compreensões, esclarecimentos e elaborações sobre inseguranças, medos, regras, diferenças e dificuldades.

Um dado relevante identificado na análise das narrativas dos entrevistados foi o olhar dos pais sobre os/ as filhos/as. Observou-se muita sensibilidade dos pais para lidarem e se atentarem a questões emocionais consideradas "difíceis" para as crianças. O entrevistado Matheus preocupou-se com a nova função da personalidade que seus filhos teriam que adotar: "Eles deixaram de ser os coitadinhos pra serem os ... exatamente os opressores. Eles mudaram por completo o paradigma da vida deles. Então pra eles foi muito complicado". Além disso, os pais perceberam que as crianças estavam inseridas em outro local, outro contexto, o que fez com que os mesmos se colocassem no lugar delas e procurassem compreender suas dificuldades e inseguranças. Conforme Machado et al. (2015) e Sampaio et al. (2018), a mudança do ambiente conhecido para um novo e desconhecido lugar pode ser dolorida e trazer inseguranças, porém é necessário que as crianças adotadas tardiamente consigam se sentir pertencentes ao lar da família adotiva, uma vez que este deverá ser seu lar permanente.

A agressividade também foi um fator que fez Maria Aparecida olhar de forma cuidadosa para seu filho, visto 
que, segundo a entrevistada, tal comportamento era, na verdade, um "pedido de socorro", ou seja, a criança se comporta de forma agressiva para ter atenção dos pais e para testar a consolidação dos vínculos e da adoção. Conforme já anunciado anteriormente, esses mecanismos de defesa ocorrem muito provavelmente porque já houve abandono real ou imaginário dos pais biológicos. Pode acontecer de alguns pais não compreenderem a dinâmica desses mecanismos, dificultando, assim, uma abertura para o fortalecimento dos vínculos. Para Sampaio et al. (2018, p. 318), "essa testagem faz parte do processo de vinculação e se configura como algo estruturante no processo de filiação e não deve ser entendida como algo destrutivo".

Crianças adotadas tardiamente que tiveram contatos e vínculos com os pais biológicos podem ter dificuldades em assumir e aceitar as funções de ser filho e possuir novo/a pai/mãe. A entrevistada Andreia relatou sobre ter de realizar uma despedida da filha para a mãe biológica:

Todo aquele trabalho de ela fazer uma despedida novamente, através de cartas, trabalhar assim, ... o que ela vai falar agora, como é que ela tá agora, que que ela vai falar pra mãe dela, como se ela tivesse saindo de casa agora, ... então fez todo esse trabalho ... era saudade da mãe. (SIC Andreia)

Ozoux-Teffaine (1987, como citado em Alvarenga \& Bittencourt, 2013) ressalta a necessidade de auxiliar a "criança abandonada precocemente e adotada tardiamente" para que a mesma consiga, aos poucos, se desligar da família biológica. Tal processo pode contribuir para que a criança se perceba como pertencente à nova família na condição de filho. Nesse sentido, ao realizar a adoção tardia, os pais precisam ser capazes de adaptar a criança à nova realidade e realizar um "trabalho de luto" em relação à família biológica (Levy, Pinho, \& Faria, 2009, p. 60 como citado em Machado et al., 2015, p. 78). Em contrapartida, Schettini et al. (2006, p. 291) afirmam que os pais adotivos devem constituir uma "convivência imaginária” com os pais biológicos da criança. As autoras afirmam ainda que, com isso, os mesmos poderão viver "seu projeto afetivo como integrado ao biológico e, por outro lado, estarão em condições de acompanhar o filho no terreno do passado para recuperar cultura, lembranças e emoções que a ele pertencem". Compreende-se, então, que não é possível manter em segredo ou apagar das memórias da criança as vivências que ocorreram anteriormente à adoção e, para isso, os pais devem trabalhar com seus filhos para que entendam seu lugar em uma nova família, mas auxiliando a criança a entender e elaborar o seu passado.

Teixeira-Filho (2010) problematiza os efeitos daquilo que se pode chamar de "segredos da adoção". Segundo o autor, é comum que algumas famílias adotivas tenham como prerrogativa fazerem da adoção um segredo. Diante da sua experiência como supervisor de estágio que atende pessoas adotadas, questiona: "O que, de fato, essa criança não pode saber? O que (ou quem) deve ser mantido na ignorância? De qual saber não se pode saber?" (Teixeira-Filho, 2010, p. 245). Seguindo suas reflexões, o autor aponta que "a imposição do segredo da adoção tem raízes históricas e seus efeitos repercutem no prognóstico da relação entre pais e filhos adotivos e nos obrigam, criticamente, a interrogar a sua função". Nessa perspectiva, o fato de se manter em segredo o passado da criança de modo 
a privá-la de suas experiências pregressas não apenas produz efeitos consideráveis na vinculação da criança com a família adotada, como também aponta para importantes relações de poder que não podem ser desconsideradas nos casos de adoção. É importante destacar que, apesar desses imaginários sobre a prerrogativa do "segredo", tal como apontado por Teixeira-Filho (2010), nenhum dos entrevistados relatou que ocultou as histórias e experiências pregressas de seus filhos. Isso provavelmente tenha relação com o bom preparo que esses pais tiveram no período pré-adoção (interesse pessoal por leituras, participação em grupos de apoio de adoção, etc.).

Após o estabelecimento de vínculos entre adotantes e adotados, é preciso que os mesmos assumam suas funções na relação familiar, a fim de garantir os sentimentos de pertencimento e vínculos parento-filiais. A participante Andreia relata que percebeu o estabelecimento dos vínculos quando suas filhas passaram a confiar nela, ou seja, o sentido de vínculo parento-filial foi atribuído a partir da confiança nos pais e no processo de adoção. Em pesquisa realizada por Orionte e Souza (2005) a respeito do significado do abandono para crianças institucionalizadas, as autoras apontaram que, mesmo com as desconfianças iniciais das crianças, observou-se entre os sujeitos pesquisados uma grande disponibilidade para estabelecer vínculos. Segundo as autoras, a vinculação com a nova família acontece de forma gradual e em um tempo singular para cada criança.

Para que ocorra a vinculação, os interlocutores relataram que é necessário que ambas as partes estejam envolvidas e interessadas em estabelecê-la. Dias et al. (2008) consideram que o sucesso do processo da adoção é resultante da maneira pela qual os pais adotivos enfren- tam e superam as dificuldades ocorridas. O entrevistado Matheus relata: “ $E$ um processo de aprendizado mútuo ... A gente também tem que aprender, os pais também aprendem". Já Luciana ressalta:

Então eu acho que essa questão do vínculo ali depende muito da gente, do teu empenho e que é uma conquista, tu vai conquistar esse amor novamente, porque a criança, ela tem uma história ... A criança, ela precisa ter uma família, ser parte de uma família. (SIC Luciana)

A questão enunciada por Luciana é muito importante, já que os vínculos não se criam apenas com expectativas ou intenções de parentalidade. É necessário se implicar, compreender e elaborar a situação da criança. Ou seja, por conta das vinculações anteriores que a criança estabeleceu, há a necessidade de trabalhar diversos aspectos subjetivos e emocionais com a criança para recolocá-la numa posição de sujeito de filho pertencente a uma nova família. Tudo isso vai depender, portanto, da construção de um sentimento de pertencimento. O sentido enunciado nas entrevistas foi de que o período de adaptação termina quando é estabelecido um sentimento de pertencimento entre todas as partes da família envolvidas no processo de vinculação parento-filial. De acordo com Araujo (2017, p. 54), "na formação do sentimento de filiação é essencial que se instale uma reciprocidade nas relações construídas ao longo da interação". Desse modo, torna-se crucial que todos estejam implicados/as nos processos de vinculações, tanto no cotidiano como na história da nova família.

Para que haja um sentimento de pertencimento na família, os adotantes necessitam sentir-se pais, isto 
é, desenvolver uma percepção sobre si como pais da criança que está se integrando à nova família. Esse sentimento ocorre de forma subjetiva e diversificada, sendo construído com a finalidade de propiciar o estabelecimento de determinadas funções desempenhadas na relação familiar, conforme podemos observar nos relatos abaixo:

Eu acho que eu me percebi como mãe no meio daquele rolo todo, de ter que fazer comida, levar pra escola, ou levar no médico e aí toda aquelas coisas e depois vem o sorriso, então aí você se percebe como mãe. (SIC Andreia)

Eu confesso, eu ria, quando eles começaram a me chamar de mãe, eu olhava pra eles e começava a rir, "eu também tô me acostumando com a ideia de ser mãe" ... Então é uma construção no cotidiano. (SIC Maria Aparecida)

Tendo em vista estes relatos, observa-se o sentido de que os pais adotivos devem também conquistar o lugar de pai/mãe na interação com a criança. Além disso, os adotantes devem criar condições para que a criança seja capaz de se perceber como parte da família e ocupando o lugar de filho. Com isso, quando o sentimento de pertencimento é estabelecido, os entrevistados percebem como uma vitória, de acordo com o que aponta Matheus: "Ah, foi assim uma missão cumprida ... foi uma vitória bem grande tu perceber que eles confiavam".

Assim sendo, os pais entrevistados não consideram que a adoção seja complexa; acreditam que o processo de adotar é semelhante a gerar um filho biológico. Além disso, relatam ain- da que não conseguem distinguir que os filhos são adotivos.

A gente fala em adoção, mas no dia-a-dia a gente nem lembra mais de adoção, porque pra gente é tão normal ... hoje em dia nem falo mais que são filhas adotivas, porque é tão normal pra gente que não precisa nem rotular. (SIC Andreia)

Os relatos apontam para um sentido de que quando são estabelecidos os vínculos parento-filiais e afetivos, os entrevistados não notam diferença quando os comparam com uma filiação biológica. Além disso, os entrevistados consideram que não é só na adoção que ocorre uma aceitação e inclusão da criança na família, mas que isso está presente também em famílias constituídas por filhos biológicos, conforme refere Matheus sobre pais biológicos e a gestação: "Por mais que eles esperassem, antes dos filhos chegarem, eles adotavam os filhos depois que eles nasciam, né? A adoção mesmo, aquela questão da proximidade do afeto, ela ia acontecendo com a relação". Assim, para Levinzon (2004, p. 25 como citado em Schettini et al., 2006, p. 287), "toda filiação é, antes de tudo, uma adoção". Ou seja, independente da forma pela qual a parentalidade ocorre, é necessário que os pais reconheçam a criança como filho. Nesse sentido, o que define o sucesso ou fracasso na vinculação parento-filial é o apoio, o amparo, a dedicação e as "trocas afetivas profundas e verdadeiras" entre os pais e filhos, independente da forma em que ocorre tal filiação. (Vargas, 1998, p. 153)

Os entrevistados demonstram que suas expectativas em relação aos vínculos eram associadas ao fato de serem percebidos como pai/mãe e ter uma relação de confiança e de troca de afetos 
entre pais e filhos. Conforme aponta Matheus: "Onde a gente tá ... Então era nisso que eu queria chegar, na criação de vínculo de pai e filho". Isso aponta para a estabilidade dos vínculos atuais, que só é possível após uma vinculação bem elaborada e desenvolvida entre os familiares.

Em relação ao processo de vinculação, os pais entrevistados consideram estar contentes e que alcançaram seus objetivos. Segundo Maria Aparecida: "eu realmente acho, assim, que eu tive a felicidade da escolha do meu coração, eu segui o meu coração. ... Eu me sinto uma mãe realizada". Com isso, observa-se que, para os entrevistados, houve o estabelecimento de vínculos afetivos e de filiação que tiveram como resultados uma satisfação e realização no tocante à adoção e à parentalidade. Percebe-se, ademais, que conseguiram alcançar suas expectativas em relação à construção de vínculos. Os entrevistados relatam experienciar sentimentos de felicidade, tendo a certeza sobre a escolha pela adoção e o sucesso da mesma.

\section{CONSIDERAÇÕES FINAIS}

A vinculação é uma construção que perpassa todo o processo de adoção, desde o momento em que os então pretendentes escolhem a parentalidade adotiva, passando por todo o processo jurídico da adoção até chegar à construção dos vínculos parentofiliais. Ao longo de nossa pesquisa, percebemos que este processo não ocorre de forma instantânea e que não há uma "receita": exige-se dedicação, desejo, afeto, persistência, tempo e compreensão.

Foi presente nos discursos dos entrevistados que estes perceberam mais aspectos positivos do que nega- tivos no processo de adoção, ou seja, não negaram a existência de dificuldades, mas as facilidades e o desejo se sobrepunham a elas. Destacaram, ainda, a percepção de que a adoção tardia pode ser mais tranquila do que a adoção convencional, principalmente por conta da capacidade da criança com mais idade de compreender, dialogar e se expressar.

Assim, destacamos os principais sentidos atribuídos aos processos de vinculação em casos de adoção tardia expressos pelos interlocutores: a necessidade de haver uma adaptação para a criança que está sendo incluída na relação familiar, possibilitando uma construção coletiva entre pais e filhos; a integração do passado da criança, construindo com ela uma compreensão e ressignificação destas vivências; a compreensão de mecanismos de defesa da criança; a promoção de sentimentos de pertencimento, na qual tanto os pais quanto os filhos adotivos assumem suas funções na dinâmica familiar.

Durante as entrevistas, percebemos que os interlocutores expressavam descontentamentos em relação ao despreparo de alguns profissionais envolvidos no processo da adoção, bem como em relação à morosidade do judiciário. Segundo os entrevistados, além de não haver a possibilidade de ocorrer um estágio de convivência previamente à adoção, muitos se sentiam "desamparados", ou seja, sem acompanhamento de uma equipe técnica responsável por eventuais cuidados e atenção à família e à criança adotada.Os interlocutores, desse modo, sinalizaram que a busca por profissionais da Psicologia, Serviço Social e Direito, bem como por grupos de apoio à adoção, se constituiu como um empreendimento individual com pouca (ou nenhuma) assistência do Estado. 
Conclui-se que um dos maiores indicadores do possível sucesso na adoção é a vinculação parento-filial. Conforme afirma Matheus: "tu deve ter paciência, espere, vai vir o resultado". Consideramos, portanto, que, para ocorrer à vinculação, é preciso que haja primeiramente paciência, desejo, afeto, compreensão. Um dos efeitos desse processo é o sentimento de amor, presente em todos os relatos dos entrevistados. Espera-se que essa pesquisa possibilite novos conhecimentos e reflexões para demais pais adotivos ou pretendentes à adoção, além de esclarecer e desmistificar algumas questões relacionadas à adoção tardia, à parentalidade e à construção de vínculos na adoção. Além disso, apontamos a necessidade de explorar o tema da adoção a partir de outros vieses e atores, seja pelas próprias crianças adotadas ou em instituições de acolhimento, pelos profissionais dessas instituições e das varas da infância e da família, pelas pessoas envolvidas em grupos de apoio à adoção e até mesmo pelos adotantes que desistiram do processo de adoção.

\section{REFERÊNCIAS}

Alvarenga, L. L. \& Bittencourt, M. I. G. F. (2013). A delicada construção de um vínculo de filiação: o papel do psicólogo em processos de adoção. Pensando familias, 17(1), 4153. Recuperado de http://pepsic. bvsalud.org/scielo.php?script=sci arttext\&pid $=$ S1679-494X2013000 $100005 \& \operatorname{lng}=\mathrm{pt} \& \mathrm{t} \operatorname{lng}=\mathrm{pt}$

Araujo, I. C. C. (2017). Tornar-se filho na perspectiva de crianças adotadas tardiamente Dissertação de Mestrado, Programa de Pós-graduação em Psicologia,Universidade Federal do Espírito Santo, Vitória, ES.
Recuperado de http://repositorio.ufes.br/bitstream/10/6876/1/ tese $9848 \quad 14.12 .17 \% 20 \mathrm{PDF} \% 20$ VER S A O \% 20 C A P A \% 20 DURA\%20FINAL.pdf

Bícca, A.\& Grzybowskil, L. S. (2014). Adoção tardia: percepções dos adotantes em relação aos períodos iniciais de adaptação. Contextos Clínicos, 7(2), 155-167. Recuperado de http://pepsic.bvsalud.org/ scielo.php?script $=$ sci arttext\&p $\underline{\mathrm{id}=S 1983-34822014000200005}$. doi: https://dx.doi.org/10.4013/ ctc. 2014.72 .04

Cananéa, A. L. C. L. (2016). Adoção tardia? Uma leitura psicanalítica. Recuperado de http://www. fundamentalpsychopathology. org.br/uploads/files/Anais $\% 20$ Congresso\%202016/51.2.pdf

Consellho Federal de Psicologia - CFP. (2012). Mudança de foco nos processos de adoção reforça papel do psicólogo. Revista Diálogos, 8(9), 36-39. Recuperado de https://edoc. site/dialogos-psicologia-juridica-pdf-free.html

Conselho Nacional de Justiça - CNJ. (2013). Encontros e Desencontros da adoção no Brasil: uma análise do Cadastro Nacional de Adoção do Conselho Nacional de Justiça. Brasília, DF. Recuperado de http:// www.cnj.jus.br/images/pesquisas-judiciarias/Publicacoes/pesq adocao brasil.pdf

Costa, N. R. A. \& Rossetti-Ferreira, M. C. (2007). Tornar-se pai e mãe em um processo de adoção tardia. Psicologia Reflexãoe Crítica, 20(3), 425-434. Recuperado de http:// www.scielo.br/pdf/prc/v20n $3 /$ a10v20n3.pdf

Dias, C. M. S. B., Silva, R. V. B., \& Fonseca, C. M. S. M. S. (2008). A adoção de crianças maiores na perspectiva dos pais adoti- 
vos. Contextos Clínicos, 1(1), 2835. Recuperado de http://pepsic. bvsalud.org/scielo.php?script=sci a r t text \& p i d = S 1983 $-34822008000100004 \& \operatorname{lng}=\mathrm{pt} \& \operatorname{th}$ $\mathrm{g}=\mathrm{pt}$

Lei n. 8.069, de 13 de julho de 1990. (1990). Dispõe sobre o Estatuto da Criança e do Adolescente e dá outras providências. Recuperado de http://www.planalto.gov.br/ccivil_03/LEIS/L8069.htm

Lei n. 12.010, de 03 de agosto de 2009. (2009). Dispõe sobre adoção; altera as Leis nos 8.069, de 13 de julho de 1990 - Estatuto da Criança e do Adolescente, e dá outras providências. Recuperado de http:// www.planalto.gov.br/ccivil 03/ ato2007-2010/2009/lei/112010.htm

Lei n. 13.509, de 22 de novembro de 2017. (2017). Dispõe sobre ado-

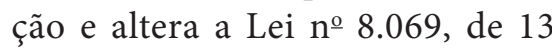
de julho de 1990 (Estatuto da Criança e do Adolescente) e dá outras atribuicões, Recuperado de http://www.planalto.gov.br/ccivil 03/ato2015-2018/2017/Lei/ L13509.htm

Machado, L. V., Ferreira, R. R., \&Seron, P. C. (2015). Adoção de crianças maiores: sobre aspectos legais e construção do vínculo afetivo. Estudos Interdisciplinares em Psicologia, 6(1), 65-81. Recuperado de http://pepsic.bvsalud.org/scielo.php?script $=$ sci a r t t e x t \& p i d = S 2236 $\underline{-64072015000100006 \& \operatorname{lng}=p t \& t \ln }$ $\mathrm{g}=\mathrm{pt}$

Ministério do Desenvolvimento Social e Combate à Fome - MDS. (2006). Plano Nacional de Promoção, Proteção e Defesa do Direito de Crianças e Adolescentes à Convivência Familiar e Comunitária. Recuperado de http://www.mds.gov.br/ webarquivos/publicacao/assisten- cia social/Cadernos/Plano Defesa CriancasAdolescentes\%20.pdf

Orionte, I. \& Souza, S. M. G. (2005). O significado do abandono para crianças institucionalizadas. Psicologia em Revista, 11(17),29-46. Recuperado dehttp://pepsic.bvsalud. org/scielo.php?script=sci arttext\& pid $=$ S1677-11682005000100003

Pinto, L. M. S. (2010). Reflexões sobre o processo de vínculos na filiação adotiva.Dissertação de Mestrado, Programa de Pós-graduação em Psicologia Clínica, Universidade Católica de Pernambuco, Recife, PE.Recuperado de http://www.unicap.br/tede/tde arquivos/1/TDE2010-05-10T204901Z-282/Publico/ dissertacao_licelia martins.pdf

Sampaio, D. S., MagallhãeS, A. S.y \&Féres-Carneiro, T. (2018). Pedras no caminho da adoção tardia: desafios para o vínculo parento-filial na percepção dos pais. Trends in Psychology, 26(1), 311-324. Recuperado de http://www.scielo.br/scielo.php?script $=$ sci a r t text \& p i d = S 2358 $-18832018000100311 \& \operatorname{lng}=e n \& n r$ $\underline{\mathrm{m}=\mathrm{iso} \& \mathrm{t} \operatorname{lng}=\mathrm{pt}}$.

Schettini, S. S. M., Amazonas, M. C. L. A., \& Dias, C. M. S. B. (2006). Famílias adotivas: identidade e diferença. Psicologia em Estudo, 11(2), 285-293. Recuperado de http:// www.scielo.br/pdf/\%0D/pe/v11n2/ v11n2a06.pdf

Spink, M. J. Pr \& Medrado, B. (2013). Produção de sentido no cotidiano: uma abordagem teórico-metodológica para análise das práticas discursivas. In M. J. P. Spink (Org.), Práticas discursivas e produção de sentidos no cotidiano (pp. 22-41). Rio de Janeiro: Centro Edelstein de Pesquisas Sociais.

Teixeira-Filho, F. S. (2010). Os segredos da adoção e o imperativo da 
matriz bioparental. Revista Estudos Feministas, 18(1), 241-262. Recuperado de https://dx.doi.org/10.1590/ S0104-026X2010000100015

Vargas, M. M. (1998). Adoção tardia: da família sonhada à família possível. São Paulo: Casa do Psicólogo.

\section{MAITÊ BROERING FERNANDES}

Bacharel em Psicologia pela Universidade do Sul de Santa Catarina (Unisul), SC.

E-mail: maibroeringf@gmail.com

\section{DANIEL KERRY DOS SANTOS}

Universidade do Sul de Santa Catarina (Unisul), Campus Grande Florianópolis. Doutor em Psicologia pela Universidade Federal de Santa Catarina (UFSC), psicólogo (CRP12/11122) e professor do curso de Psicologia da Universidade do Sul de Santa Catarina (Unisul).

E-mail: dakerry@gmail.com 